\title{
Corrigendum
}

\section{Multiple cycles of dose-intensive chemotherapy with repeated stem cell support as induction treatment in metastatic breast cancer: a feasibility study}

S García-Rayo, J Pérez-Calvo, S Martín-Algarra, R Martínez-Monge, O Fernández-Hidalgo, L Subirá, M Martínez-Aguillo, J Rebollo, I Azinovic and A Brugarolas

Bone Marrow Transplantation 2001; 28: 235-242

Since publication of the above paper, the author has identified an error in his paper. Figures 5 and 6 were interchanged. Please see below the correct figures with the correct figure legends.

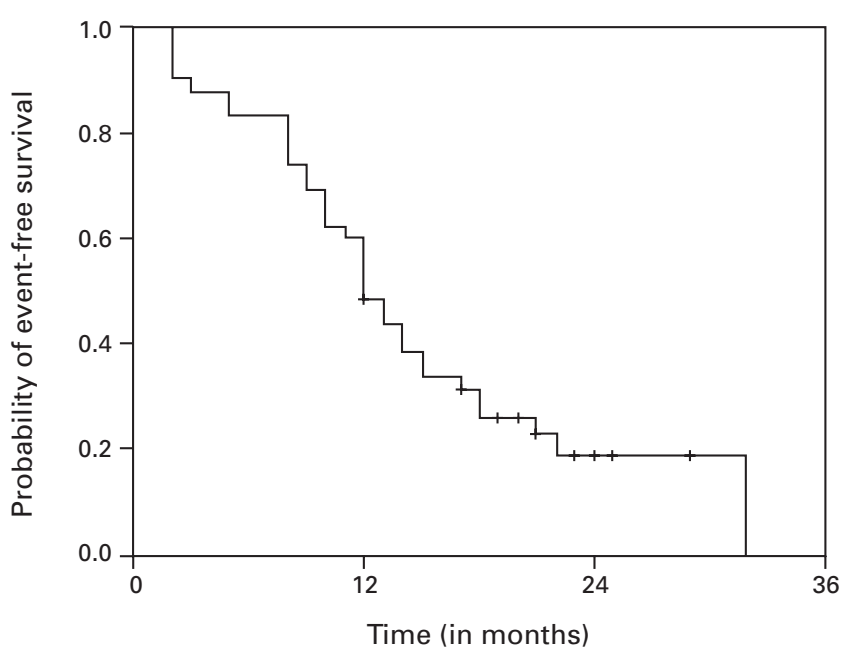

Figure 5 Event-free survival.

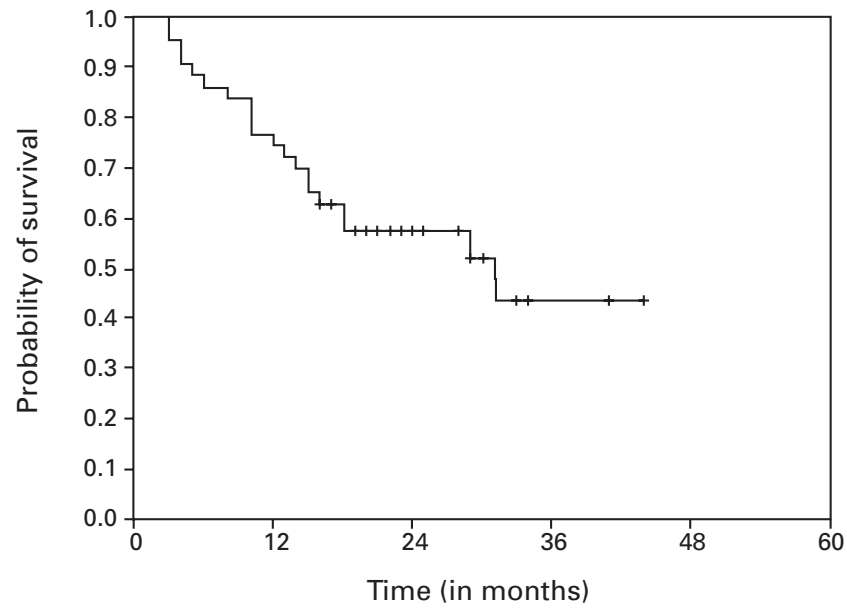

Figure 6 Overall survival. 